\title{
Exploring and Assessing Innovative Approaches to Utilizing Waste as a Resource: Toward Co-Benefits
}

\author{
Xudong Chen ${ }^{1,2}$, Tsuyoshi Fujita ${ }^{2}$, Yong Geng ${ }^{3}$ and Fengming $\mathrm{Xi}^{3}$ \\ ${ }^{1}$ Graduate School of Environmental Studies, Nagoya University \\ ${ }^{2}$ National Institute for Environmental Studies \\ Institute of Applied Ecology, Chinese Academy of Sciences \\ 1,2Japan \\ ${ }^{3}$ China
}

\section{Introduction}

Waste is an inevitable byproduct of human activity. In the last two centuries, waste management has passed through a series of transitions in terms of treatment and disposal technologies, as well as in administrative systems and in people's attitudes. Waste managers, engineers, planners, and researchers have contributed to these transitions by responding to issues such as public health, disposal capacity, more-rigorous environmental standards, and public and political pressures (Louis, 2004; Tarr, 1985). More recently, studies on waste management have emphasized the 3Rs (Reduce, Reuse, and Recycle). As a result of the efforts of practitioners and researchers, considerable achievements in waste handling have been realized in a number of countries. The questions that we currently face are "What forthcoming issues related to waste management do we need to respond to?" and "What will be the appropriate methods for addressing these issues in research?" In this chapter, we will explore some of the pressing issues, and we will propose a research framework for assessing the options available for responding to them.

\section{Shifting toward utilizing waste as a resource}

Nowadays, the macro-level pressures that affect waste management are more diverse and more complicated than ever, while the pressures that previously drove transitions in waste management remain. For example, the impact of waste on public health continues to receive great attention. Wastes that contain hazardous materials, such as waste electrical and electronic equipment, scrap automobiles, and medical waste, require special treatment and disposal (Achillas et al., 2010; K. C. Chen et al., 2010; Jang et al., 2006). The shortage of disposal capacity, especially landfilling capacity, continues to be a major driver for volume reduction and for diversion of waste from landfill (Bai \& Sutanto, 2002; Geng et al., 2010; Jin et al., 2006). Despite progress in technologies and the strengthening of environmental standards, the problems of NIMBY ('not in my backyard') attitudes and political pressure remain unsolved. For example, as a result of insufficient public participation during the 
planning stage, difficulties were encountered in siting of new landfills in Ontario, Canada, and exporting of waste to Michigan in the USA for landfilling caused political tensions between the two countries (Hostovsky, 2006). Similarly, public opposition in Beijing resulted in the cancelation of the construction of a new incineration plant in 2007 (SEPA, 2007).

In addition, pressures arising from environmental and economic problems have rapidly come to prominence in recent years, and these have become new drivers for further waste reduction, reuse, and recycling. Depletion in resources has encouraged recycling of scarce materials (e.g. rare metals) from wastes or, more generally, urban mining, i.e. recycling of resources from urban stock (Klinglmair \& Fellner, 2010; Ongondo et al.). As the development of the recycling market has created new business opportunities, economic drivers have come into play. For example, in the USA, eco-industrial development, including the encouragement of industrial symbiosis and the development of eco-industrial parks, was originally considered to be an economic development strategy (Deppe et al., 2000). The eco-town program in Japan had the dual objectives of solving waste-management problems and stimulating industrial development (van Berkel et al., 2009). In China, a circular economy based on reduction, reuse, and recycling appeared to be a practical strategy for sustainable development of the economy and society (Yuan et al., 2006). Currently, attempts to mitigate climate change affect decisions on a wide range of environmental and economic activities, including waste management. Cleary (2009) reviewed 20 studies on life cycle assessment (LCA) in waste management recently published in English-language peer-reviewed journals and found that 19 of these studies assessed global warming potentials, i.e., emissions of anthropogenic greenhouse gases (GHG). In practical terms, carbon credits provide an incentive for waste disposals in a manner that reduces GHG emissions in comparison with conventional practices. For example, as of February 24, 2011, of 2845 projects registered under the United Nations Framework Convention on Climate Change's Clean Development Mechanism (UNFCC CDM), 516 $(18 \%)$ involved waste handling and disposal; this is the second largest category, following that of the energy industry (http://cdm.unfccc.int/Projects/projsearch.html).

Under these circumstances of multidimensional pressures on waste management, merely diverting wastes from landfills and increasing recycling rates might no longer be a sufficient response. The combination of pressures demands an improvement in the ecoefficiency of recycling and in utilizing wastes as resources to fulfill multiple purposes or, in other words, seeking co-benefits from waste management. Admittedly, local conditions in various countries and regions differ from one another and, as a result, they might have different priorities in terms of their objectives. Despite these differences, however, there is a common goal of improving efficiency in processing and utilization of recyclable wastes after source separation to achieve greater environmental and economic benefits.

\section{Assessment of waste treatment and disposal}

To improve the efficiency of recycling, it is important that various options be considered and compared during the planning stage. Among various evaluation methods, LCA is a methodology that is widely used in assessing impacts of waste management. LCA can be used to assess and compare the potential impacts of various treatments and disposal methods on the waste hierarchy (Banar et al., 2009; Finnveden et al., 2005; Liamsanguan \& Gheewala, 2008). LCA can also be used to evaluate the applications of one method or of one type of facility on different scales (Habara et al., 2002; Lundie \& Peters, 2005; 
Wanichpongpan \& Gheewala, 2007). It can also be used to assess various treatment methods for a particular type of waste (Al-Salem et al., 2009; Cadena et al., 2009; Lundie \& Peters, 2005). In most of these studies, the LCA methodology is used to assess the possible consequences of certain decisions (e.g., applying different treatment methods or establishing facilities in different locations or at different scales) by setting up multiple scenarios that represent the various options. Such an approach is often referred to as change-oriented or consequential LCA, and it describes how environmentally relevant physical flows might change in response to possible decisions (Ekvall \& Weidema, 2004; Finnveden et al., 2009).

The consequential LCA method also fits the purpose of our research: to identify the co-benefits of efficient utilization of waste. For this purpose, we need to be able to consider several aspects when simulating possible consequences. The first aspect involves the efficiencies and impacts of recycling technologies. A number of studies have been performed in this area. Unlike landfill and incineration, for which most countries have already issued technical standards, recycling involves a combination of many different technologies with no clear standards. For example, waste plastics can be treated through various mechanical recycling, chemical recycling, or energy recovery processes (Al-Salem et al., 2009); sewage sludge can be treated by agricultural landspreading, incineration, wet oxidation, pyrolysis, incineration in cement kilns, or anaerobic digestion (Houillon \& Jolliet, 2005); and food waste can be treated by composting, anaerobic digestion, or wet or dry feeding (Kim \& Kim, 2010; Levis et al., 2010). These technologies co-exist for a combination of economic and environmental reasons. No single technology appears to dominate in practice, and research efforts have been made to evaluate these technologies from various perspectives.

The other aspect that needs to be considered is that of policies related to recycling, waste reduction, and source separation. LCA studies on waste management typically assess the impacts of managing waste on a unit-weight basis (per kg or per ton) (Ekvall et al., 2007). Results from such studies can be readily compared with one another to identify efficient technologies, but they do not reflect different waste-management policies. In addition to treatment technologies, waste management also involves various regulatory and economic instruments, for example, "pay-as-you-throw" policies, designed to encourage waste separation and recycling. It is therefore necessary to account for the total amount of waste generated in a municipality or a region as a functional unit and to consider the potentials for reduction and for recycling if appropriate policies were to be implemented. In the next section, we introduce a simulation system that combines alternative environmental technologies and policies; we also present two examples of applications of this system.

\section{Research framework and examples of application}

Fujita and his co-workers have developed a simulation system for assessing urban environmental technology (Fujita et al., 2007; Nagasawa et al., 2007; Wong et al., 2008). The model consists of three main parts: a database, a technology inventory, and a set of environmental policy options. The application of this simulation system is not limited to waste management. Some examples related to recycling are illustrated in Figure 1. For better evaluation of the environmental impacts and costs of waste collection and transportation, the database is built on the basis of a geographic information system (GIS) when digitally based maps and spatial distribution data are available, for example, for road networks and the distribution of populations and waste generation. The technology inventory contains input and output data on waste recycling and disposal technologies, as well as emission factors, and it embodies environmental impacts of utilities. Finally, the model contains 
policy options (including various waste-reduction and recycling policies) that could be implemented in the city being studied.

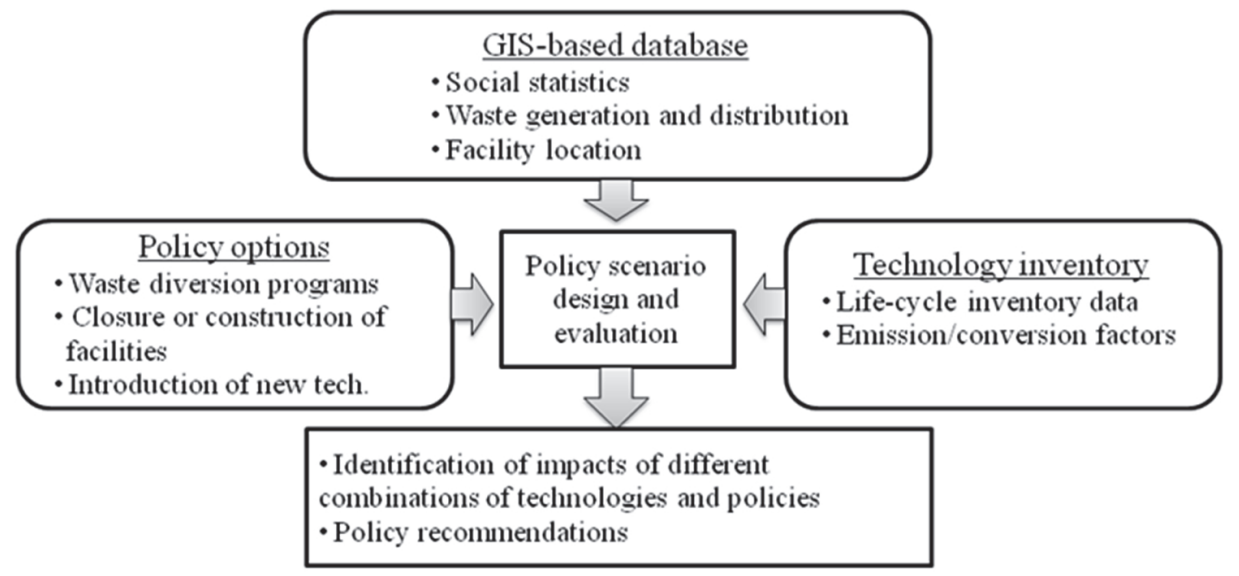

Fig. 1. Urban environmental technology simulation system for recycling

Scenario design and evaluation are based on the LCA approach in terms of selecting the system boundary and functional unit for assessment. Provided that data are available, the impact categories can contain key aspects that are of concern to the city under study, including environmental impacts and economic costs and benefits. For various combinations of policies and technologies, one can set up multiple scenarios to simulate possible consequences. This simulation system can help decision makers to assess potential consequences of alternative options. Below, we present two examples of our recent studies. The first was a case study on options for expanding recycling programs by utilizing existing facilities in Kawasaki, Japan, and the second was a case study on transferring advanced recycling technologies to Shenyang, China.

Case Study 1: Economic costs and environmental impacts of expanding recycling programs by utilizing existing industrial facilities in Kawasaki

Kawasaki city is the ninth most populous city in Japan, with a total population of 1.4 million, and is located between Tokyo and Yokohama. This area is one of the industrial cores of Japan that supported the country's industrial development and economic growth during the last century. Kawasaki is also a front-runner in environmental protection and recycling businesses. The Kawasaki Eco-Town was among the first group of eco-towns designated in 1997 and, as a result, a number of recycling facilities are located there. Five facilities were subsidized by government, including facilities for recycling waste plastic as a reductant in blast furnaces for iron production, for recycling of hard-to-recycle paper (e.g., train tickets or confidential documents in sealed boxes) to produce toilet paper, for recycling of polyethylene terephthalate (PET) to monomers for re-synthesis of PET, for recycling of waste plastics to produce syngas for ammonia production, and for recycling of waste plastics to produce concrete formworks (GEC, 2005). Nonsubsidized recycling facilities in Kawasaki include a facility for recycling household electronic waste and a cement plant that uses wastes such as dehydration cake from wastewater treatment, ash from sludge incineration, waste plastics, and wood chips as feedstocks and fuels for cement production. 
With these recycling and industrial facilities, a number of industrial and urban symbiotic networks have been established (for details, see Geng et al., 2010). These industrial facilities still have sufficient spare capacity to receive additional wastes from municipal sources. The city government has examined the possibility of expanding recycling programs and utilizing greater quantities of recyclable wastes from municipal sources in these facilities.

With regard to the existing facilities, we considered recycling of mixed waste paper and non-PET packaging waste plastics from households, and of organic wastes from commercial sources such as cafeterias, restaurants, and convenience stores. These wastes are currently incinerated but, if properly separated, could be recycled at the existing facilities. The data available in Kawasaki allowed us to develop a spatial database for the distribution of the population in 1-km meshes, as well as for the positions of commercial facilities and of waste recycling, treatment, and disposal facilities. By assuming that the per capita generation of waste plastics and paper is the same for all people, we projected the distribution of the relevant wastes and we calculated the transportation distance based on the road network. We set up four scenarios, in addition to the business-as-usual (BaU) scenario, to evaluate the recycling of each type of waste separately and of all three types together (Table 1).

\begin{tabular}{|l|l|l|}
\hline Scenario & Additional recycling program & Technology \\
\hline BaU & n/a & n/a \\
\hline Mixed paper & $\begin{array}{l}\text { Mixed paper from municipal } \\
\text { sources }\end{array}$ & Producing toilet paper \\
\hline Plastics & $\begin{array}{l}\text { Mixed packaging plastics from } \\
\text { municipal sources }\end{array}$ & $\begin{array}{l}\text { Utilization as reductants in blast } \\
\text { furnaces for iron production }\end{array}$ \\
\hline Organics & $\begin{array}{l}\text { Organic waste from commercial } \\
\text { sources }\end{array}$ & $\begin{array}{l}\text { Recycling through anaerobic } \\
\text { digestion to production biogas } \\
\text { for electricity generation; } \\
\text { residue used for cement } \\
\text { production }\end{array}$ \\
\hline All & All three of the above & All three of the above \\
\hline
\end{tabular}

Table 1. Scenarios for expanding recycling programs in Kawasaki, Japan

The system boundary for the assessment encompasses (1) waste collection, transportation, and pretreatment of waste, (2) the processing process, (3) the embodied environmental burden of the replaced products, and (4) the impacts of the treatment and disposal of waste that are avoided as a result of recycling. The functional unit is the total amount of waste in Kawasaki in 2015. Recycling rates of mixed paper, mixed plastics, and organic wastes were set at $62 \%, 69 \%$, and $30 \%$ respectively in accordance with the objectives for 2015 set by the Japanese government. A total of 21 kilotons of waste paper, 18 kilotons of waste plastics, and 15 kilotons of organic wastes are expected to be separated in 2015 (for details, see Geng et al., 2010). The remaining garbage is sent to the four incinerators in Kawasaki that are equipped for electricity generation and heat recovery. To reduce transportation costs and to improve the separation of waste paper and plastics, transfer centers would be required for storing, compressing, and baling the materials. We assumed that two such centers would be built to handle waste paper and waste plastics, respectively. Source-separated waste paper or/and plastics would be collected by trucks operating on the road network and would be delivered to the nearest transfer center, from where they would be transported to existing 
recycling facilities. In the "organics" scenario, we assumed that a biogas plant capable of generating power from methane generated by fermentation of organic waste would be built. We also assumed that these new facilities would be capable of operating for 25 years without major renovation; the initial impacts of construction were therefore averaged over 25 years. We focused on three categories of impact that are of great concern in Japan: GHG emissions (i.e. global warming potential), landfill reduction, and financial costs. In a similar manner to our assessment of environmental impacts, we also considered the costs of collection, transportation, and pretreatment, as well as the costs of construction and process operation, and the small commission costs for industrial facilities to receive wastes. Initial investments for new facilities were also averaged over 25 years.

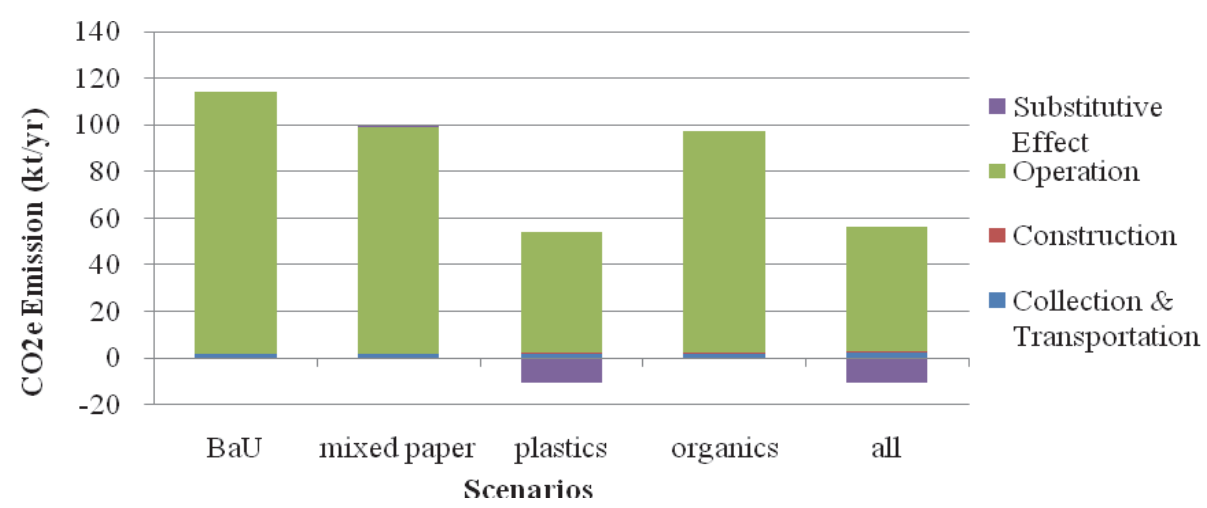

[Source: by the authors based on previous results (Geng et al., 2010).]

Fig. 2. GHG emissions for various recycling expansion scenarios in Kawasaki

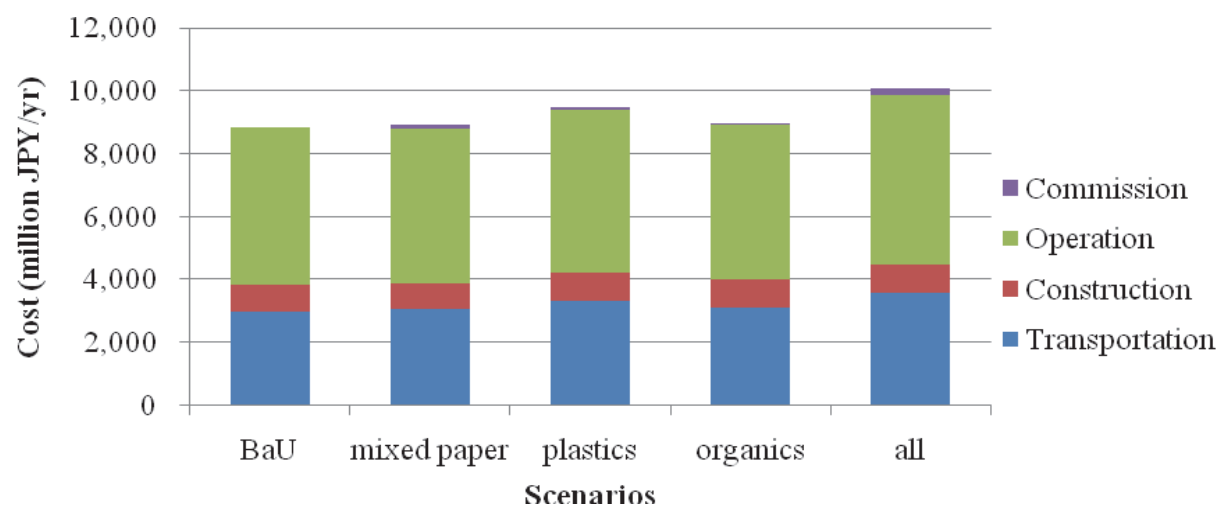

[Source: by the authors based on previous results (Geng et al., 2010)].

Fig. 3. Financial costs of recycling for various expansion scenarios in Kawasaki

The results show that emissions of up to 70 kilotons of $\mathrm{CO}_{2}$-equivalent could be eliminated annually (Figure 2). Operations, particularly the incineration process, contribute most to the 
$\mathrm{CO}_{2}$ emissions. Waste collection and transportation and the construction of new facilities account for only a small proportion of the total emissions (below 5\% in all scenarios). Reduction by material substitution varies markedly among the scenarios, depending on emissions from processing and the embodied emissions in the materials replaced. Recycling plastics results in a considerable reduction in $\mathrm{CO}_{2}$ emissions because it replaces coke, a carbon-rich feedstock for blast furnaces. By recycling mixed paper, plastics, and organic waste, inputs to landfill can be reduced by 3.2, 2.7, and 2.3 kilotons, respectively. Unsurprisingly, the total costs of waste management would increase on launching additional recycling programs (Figure 3). With such investment in new recycling programs and facilities, the city could gain environmental and economic co-benefits. Besides reductions in GHG emissions and in wastes to be landfilled, there are several benefits that are beyond the assessment boundaries of this study, such as reductions in the consumption of coal and coke, creation of new jobs, and stimulation of industrial development.

Case Study 2: Environmental impacts of transferring recycling technologies from Japan to China

A lack of efficient waste-treatment technologies is a frequent problem in developing countries. One shortcut for resolving this problem is the transfer of the necessary technologies from developed countries. Although introducing advanced technologies can, to some extent, provide environmental benefits, it is still necessary to understand which technologies are suitable for a particular locality. In this case study, we investigated the potential environmental impacts of transferring waste-plastic recycling technologies from Japan to Shenyang City, China.

Shenyang City is the capital city of Liaoning Province in northeastern China, with a total population of 7.8 million in 2009. The Shenyang Sanitation Research Institute reported that about 3 million tons of municipal solid waste (MSW) were generated in Shenyang in 2008, of which 2.13 million tons were generated within the urban area (Sun et al., 2008). Landfill is currently the major method of disposal of MSW. In the urban area, 1.85 million tons of MSW were landfilled in 2008 (Shenyang Statistical Yearbook, 2009). The remainder (0.28 million tons) was recycled, sold to the secondhand market, or dumped illegally. Taken together, plastics and rubber form the second largest category of MSW after food waste, accounting for $15 \%$ of the waste to be landfilled.

Because recyclable wastes have mainly been collected by the informal sector in China, data on the total amounts and characteristics of recyclable wastes are difficult to obtain (Chen et al., 2010). For better management of renewable resources, the Shenyang Supply and Marketing Cooperative Association (SMCA) undertook a comprehensive survey and an onsite investigation on renewable resources in Shenyang in 2009. The investigation (Wang et al., 2009) showed that the total amount of waste plastics produced in Shenyang in 2008 was 631 kilotons, of which 621 kilotons were traded in two marketplaces, and 10 kilotons were delivered to processors directly from redemption centers and junk-buyers. About one-third of these waste plastics consisted of PET, 5\% was polystyrene foam, and the remainder consisted of polyethylene (PE), polypropylene (PP), polystyrene (PS), polyvinyl chloride (PVC), and acrylonitrile-butadiene-styrene resin (ABS), among others. These waste plastics were collected from various sources, including domestic and foreign sources (for details, see Chen et al., 2011). Collected waste plastics were usually manually separated, washed, and shredded or granulated to form pellets or granules. Most such treatments were undertaken in small informal workshops without any controls over emissions. Approximately one-third of the plastic pellets were utilized in Shenyang. All the PET and more than half the mixed plastics were transported to other provinces. Hebei province, over $800 \mathrm{~km}$ away, was the major destination, receiving around four-fifths of the exported waste plastics. 
We focused on the exported non-PET plastics, because these could be utilized in more efficient ways locally if advanced treatment technologies were available. Japanese eco-towns have developed a number of plastic-recycling technologies (Van Berkel et al., 2009). Waste plastics can be converted through mechanical recycling, chemical recycling, or energyrecovery processes into products that replace virgin materials, such as plastic resins, lumber, fossil fuels, or feedstock for industrial facilities (Al-Salem et al., 2009; JCPRA, 2007). In the existing recycling process [the business-as-usual (BaU) scenario], waste plastics are shredded into pellets and granules. We assumed that PP and PE are recycled to produce plastic resins (50\% PP and 50\% PE), and the remainder are assumed to replace wooden products. This recycling process is actually down-cycling, and therefore a $10 \%$ material loss and a $20 \%$ of loss in quality were assumed (Astrup et al., 2009). We examined four alternative technologies. The first was recycling of plastics to produce plastic boards (known as NF boards) as replacements for wooden boards for concrete formwork. The second was the production of refuse plastic fuel (RPF) from shredded plastics as a source of energy to replace coal or other fossil fuels. The third was gasification of plastics to produce syngas to replace natural gas for the production of ammonia. The final technology involved the use of waste plastics material as a reductant in blast furnaces for the production of iron. Input and output data for these technologies were based on facilities in Japan and were adjusted according to the composition of waste in Shenyang (see detailed LCI data in Chen et al., 2011). Only appropriate compositions were treated by these various technologies. For each recycled product, products with an equivalent function were determined.

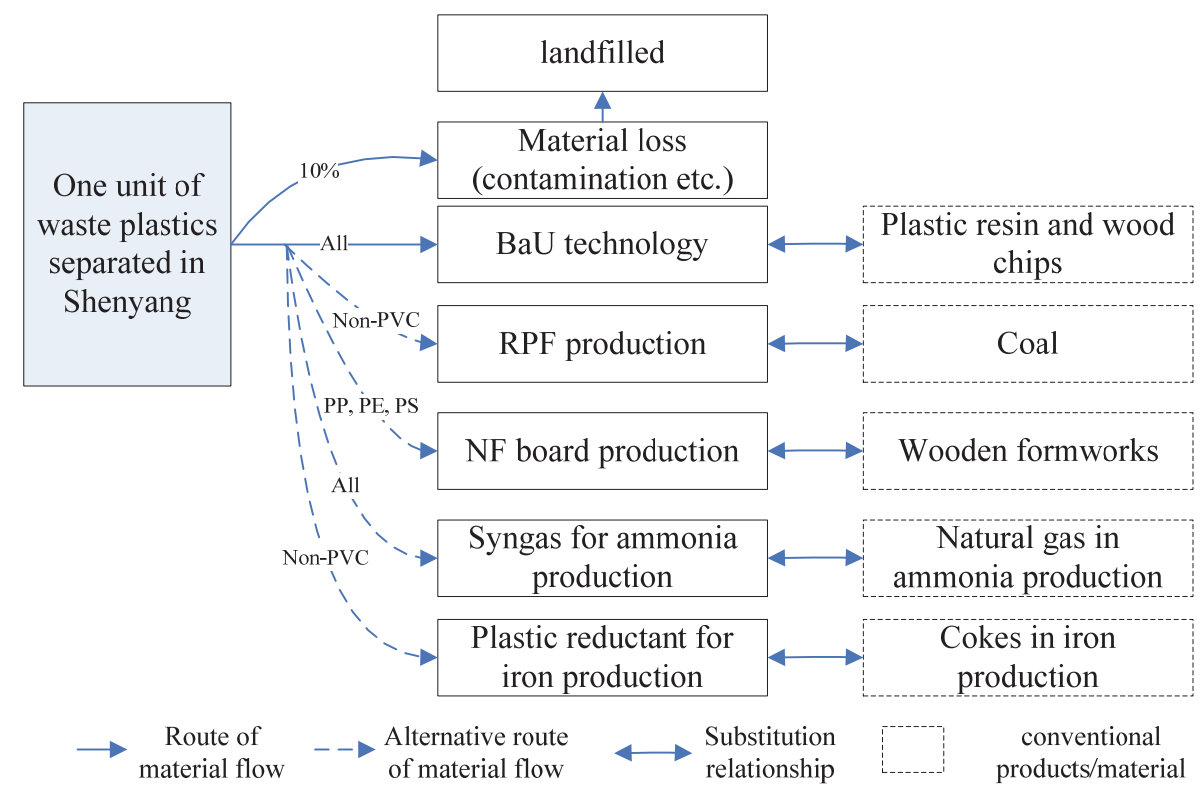

Fig. 4. Recycling technologies and substituted products with equivalent function

As in the previous case, the system boundary for the assessment included waste transportation, processing, the embodied impacts in the replaced products, and the avoided impacts of waste disposal. Waste plastics were considered to be delivered by freight trucks, as presently. Because Shenyang is located in a heavily industrialized region, it is surrounded 
by many large industrial facilities. An ammonia plant with an annual output of 322 kilotons is located in Panjin, near the Liaohe oilfield (about $160 \mathrm{~km}$ southeast of Shenyang), and two iron plants with a total annual output over two million tons are located in Anshan $(110 \mathrm{~km}$ from Shenyang) and Benxi $(80 \mathrm{~km})$, respectively. We assumed that recycled reductants and syngas could be used in these facilities. RPF and plastic formworks (NF boards) were assumed to be consumed locally. In addition, this case involves "open-loop" recycling technologies that produce products that replace various types of product on the open market (e.g., plastic formworks replacing wooden formworks). Because the compositions of the recycled product and the substituted product differ from one another, their disposal was also included. Because we focused on waste plastics in this case, the functional unit was waste plastics exported to other provinces and landfilled without utilization. The total amount of the former is about 210 kilotons, and that of the latter was estimated to be about 185 kilotons. The impacts assessed in this case included global warming potential (measured in terms of emissions of tons of $\mathrm{CO}_{2}$-equivalent, or $\mathrm{tCO}_{2} \mathrm{e}$ ) and fossil-fuel savings (by ton coal-equivalent, or tce). These categories of impacts are currently of great concern in China because, at the 2009 United Nations Climate Change Conference, held in Copenhagen, Denmark, China pledged to reduce the intensity of carbon dioxide emissions per unit of gross domestic product (GDP) in 2020 by $40-45 \%$ compared with the level in 2005 , and to increase the proportion of nonfossil fuels in its primary energy consumption to approximately $15 \%$ by 2020 (Xinhuan News Agency, 2009).

In addition to considering the introduction of technologies, we also considered the impacts of cascading use of waste plastics by mechanical and chemical recycling technologies, lowering the embodied impacts of electricity through national efforts to promote renewable energy, and launching new waste-plastic recycling programs to collect material currently being landfilled but which could be utilized by Japanese technologies (Table 2). The recycling rate of the new programs was assumed to be $50 \%$.

The results for eight scenarios are summarized in Figure 5. The NF board-production scenario showed the largest potential among the individual technologies in terms of reducing GHG emissions (254 kilo- $\mathrm{tCO}_{2} \mathrm{e} / \mathrm{yr}$ ). Much of this reduction is attributed to avoiding landfilling of wooden formworks, because wood undergoes partially biodegradation to form methane. The production of RPF provides the greatest saving in fossil-fuel consumption among the individual technologies, as it directly replaces coal, and the production process consumes little energy. Synergies between various technologies could provide additional environmental benefits. As shown in the 'NF + RPF' scenario, cascading utilization of waste plastics could bring greater reductions in GHG emissions than could any individual technology. The final two scenarios tested the impacts of changes in the carbon intensity of electricity and the operation of new waste-recycling programs. These two factors are closely related to the potential environmental gains achievable by applying the technologies. In comparison with the 'NF + RPF' scenario, a 15\% reduction in the carbon intensity of electricity could lead to an additional 93 kilo- $\mathrm{tCO}_{2} \mathrm{e} / \mathrm{yr}(34 \%)$ reduction in GHG emissions and a 12 kilo-tce/yr (12\%) saving in fossil fuels. These results indicate the existence of a synergy between clean energy and recycling/energy recovery technologies. As an industrial activity, the recycling process itself consumes electricity. If the carbon intensity of the electricity were to drop, recycling would achieve a greater reduction in GHG emissions whereas collecting landfill gases for electricity production would achieve a smaller reduction. The waste-recycling program could potentially permit the use of 92 kilotons of plastics that are currently landfilled. This new recycling program would result in an additional 41 kilo-tCO $\mathrm{CO}_{2} \mathrm{e} / \mathrm{yr}(11 \%)$ reduction in GHG emissions and a 72 kilo-tce/yr $(68 \%)$ saving in fossil fuels. 


\begin{tabular}{|c|c|c|c|}
\hline Scenario & $\begin{array}{l}\text { Introduction of alternative } \\
\text { technology }\end{array}$ & $\begin{array}{l}\text { Carbon intensity } \\
\text { of electricity }\end{array}$ & $\begin{array}{l}\text { New recycling } \\
\text { program }\end{array}$ \\
\hline $\mathrm{BaU}$ & - & - & - \\
\hline $\begin{array}{l}\text { NF board } \\
\text { (NF) }\end{array}$ & $\begin{array}{l}\text { Recycling waste plastics to produce } \\
\text { NF boards }\end{array}$ & - & - \\
\hline RPF & $\begin{array}{l}\text { Recycling waste plastics to produce } \\
\text { fuel to replace fossil fuels }\end{array}$ & - & - \\
\hline $\begin{array}{l}\text { Syngas for } \\
\text { ammonia } \\
\text { production } \\
\text { (Syngas) }\end{array}$ & $\begin{array}{l}\text { Gasifying waste plastics to produce } \\
\text { syngas for ammonia production }\end{array}$ & - & - \\
\hline Reductant & $\begin{array}{l}\text { Recycling waste plastics to produce } \\
\text { reductant for iron production }\end{array}$ & - & - \\
\hline $\mathrm{NF}+\mathrm{RPF}$ & $\begin{array}{l}\text { Recycling waste plastic to produce } \\
\text { NF boards and producing fuel to } \\
\text { replace fossil fuels from used NF } \\
\text { boards }\end{array}$ & - & - \\
\hline $\begin{array}{l}\text { Reduced } \\
\text { carbon } \\
\text { intensity of } \\
\text { electricity } \\
\text { (RCI) }\end{array}$ & As above & $\begin{array}{l}\text { The carbon } \\
\text { intensity of } \\
\text { electricity is } \\
\text { decreased by } 15 \%\end{array}$ & - \\
\hline $\begin{array}{l}\text { Waste } \\
\text { recycling } \\
\text { program } \\
\text { (WRP) }\end{array}$ & As above & $\begin{array}{l}\text { The same as in } \\
\text { 'reduced carbon } \\
\text { intensity' } \\
\text { scenario }\end{array}$ & $\begin{array}{l}\text { Rolling out new a } \\
\text { recycling program } \\
\text { to divert waste } \\
\text { plastics from } \\
\text { landfill }\end{array}$ \\
\hline
\end{tabular}

Table 2. Scenarios for transferring waste-plastic recycling technologies to Shenyang, China

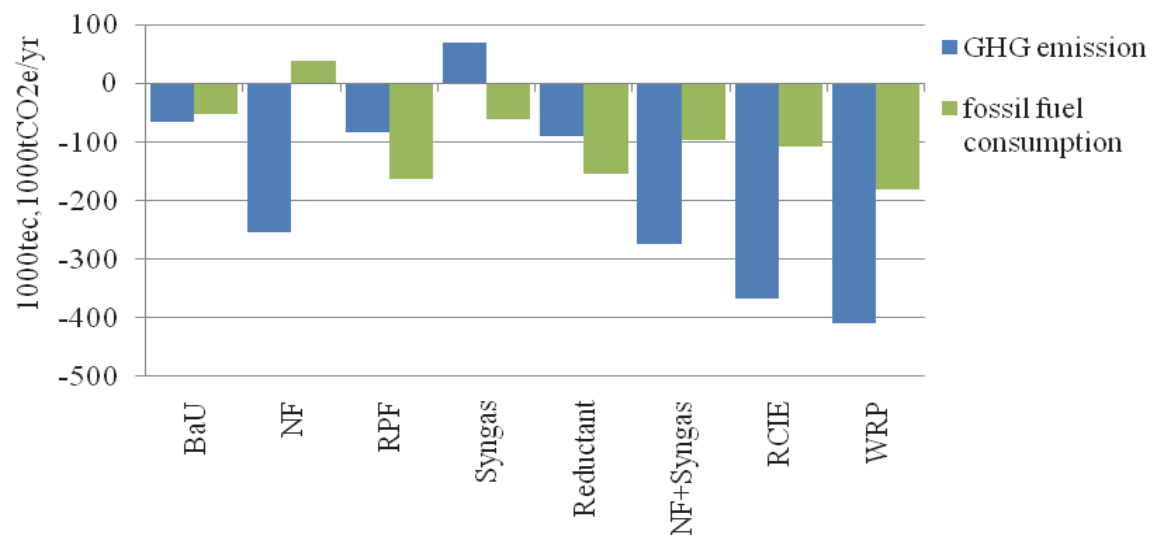

[Source: by the authors based on previous results (Chen et al., 2011)]

Fig. 5. GHG emissions and fossil fuel consumption for the various scenarios (BaU: business as usual, NF: NF board production, RPF: refuse plastic fuel, RCIE: reduced carbon intensity of electricity, WRP: launch of waste recycling program) 


\section{Discussions}

The two cases discussed in this chapter confirmed the view that recycling would lead to greater environmental benefits than incineration and landfilling. If proper technologies are chosen and there are dependable supplies of separated wastes and a reliable demand for recycled products, more recycling would provide additional environmental benefits. However, by recycling one unit of waste, different recycling technologies would realize different benefits. Their efficiencies vary because of differences in the properties of the treated wastes (such as its composition and level of contamination), in the properties of the replaced products (embodied environmental impacts), in the efficiency of processing, in emission factors, and in the current practices taken as baselines for measuring reductions. As shown in the two cases discussed above, recycling of mixed paper, plastics, and organic wastes can result in different levels of reduction in GHG emissions. Furthermore, recycling plastics by different technologies also leads to different levels of reductions in GHG emissions and in fossil-fuel savings. The compositions of waste plastics in Shenyang and Japan provide different results. Although PET bottles are usually separated because of the high market value of PET pellets and fibers, the compositions of the remaining mixed plastics remain quite different. Because of these differences, the same recycling technology would have different product yield ratios and energy efficiencies in Shenyang than in Japan. Emission factors in the two cases are also different. For example, the embodied GHG emissions for electricity in Shenyang are $1.13 \mathrm{~kg}$ $\mathrm{CO}_{2} \mathrm{e} / \mathrm{kWh}$, whereas those in Japan are only $0.55 \mathrm{~kg}-\mathrm{CO}_{2} \mathrm{e} / \mathrm{kWh}$, because the former are generated mostly in coal-fired power plants and the latter come from multiple sources, including carbon-free sources such as nuclear power and solar energy.

\begin{tabular}{|c|c|c|c|c|c|c|c|c|}
\hline \multicolumn{2}{|c|}{ Composition } & $P E$ & $\mathrm{PP}$ & PS & PET & PVC & Other & Moisture \\
\hline \multicolumn{2}{|c|}{ in Shenyang* } & $13 \%$ & $13 \%$ & $3 \%$ & $31 \%$ & $13 \%$ & $25 \%$ & $3 \%$ \\
\hline \multicolumn{2}{|c|}{ in Japan** } & $30 \%$ & $21 \%$ & $18 \%$ & $14 \%$ & $5 \%$ & $5 \%$ & $7 \%$ \\
\hline $\mathrm{LHV}^{* *}$ & $\mathrm{~kJ} / \mathrm{kg}$ & 46046 & 43953 & 40186 & 23023 & 24070 & - & -2512 \\
\hline $\mathrm{CO}_{2}{ }^{* *}$ & $\mathrm{~kg}-\mathrm{CO}_{2} / \mathrm{kg}$ & 3.143 & 3.143 & 3.385 & 2.292 & 1.408 & - & 0 \\
\hline
\end{tabular}

Source: * (Chen et al., 2011); ** (JCPRA, 2007).

Table 3. Waste plastic compositions in Shenyang and Japan

Moreover, when counting the avoided impacts of waste disposal, one has to determine how the waste might otherwise be disposed of under typical conditions (usually the common practice at the time). These typical conditions become the baseline against which emission reduction and other environmental benefits are counted. The baselines in different countries can be different, and therefore the benefits of the same technology can also be different. As shown in the two examples discussed above, whereas in Japan the baseline is incineration, in China it is landfilling. Consequently, recycling waste composed of anthropogenic carbon (e.g., plastics) in Japan would result in greater reduction in GHG emissions that in China, because incinerating plastics releases anthropogenic GHG emissions, whereas landfilling plastics, as in China, releases no emissions. On the other hand, recycling biodegradable wastes such as organics and wooden wastes in Japan results in a smaller reduction in GHG emissions, because emissions from incinerating organics would be considered carbon neutral, whereas landfilling organics would produce landfill gases that contains methane, which according to 
the IPCC Guideline has 21 times the global-warming potential of $\mathrm{CO}_{2}$. Consequently, the environmental benefits of recycling technologies depend on local conditions, and it is necessary to take these conditions carefully into consideration in case studies.

Methodologically, there is considerable scope for improving the simulation system applied in the case studies above. First, it fails to address several important factors that affect future scenarios. For example, the models analyze scenarios based on the present conditions or on planned conditions in the future, but they cannot project changes in the amount of waste generation and composition. The factors that influence waste-generation rates include household size, residency type, age groups, employment, tipping fees, GDP, education, culture, geography, and climate (Shan, 2010). As many countries are (or will) experience aging and shrinking of their populations or will undergo rapid economic development, some of these factors will change dramatically. Waste generation and composition are also expected to change. Some of these factors can be internalized in the models to make the functional unit more dynamic and closer to reality. Secondly, during our involvement in real projects entailing transfer of recycling technologies from Japan to China, we realized that, as a compromise between high efficiency and the high costs of equipments and facilities, in some cases only partial set of facilities, usually the core parts, are transferred, and these are supplemented by local equipment or by manual work. In such cases, data on input/output and costs derived from surveys on existing facilities need to be amended accordingly. More importantly, by analyzing the costs and environmental impacts of various combinations of transferred and local technologies, we could provide useful information for decision makers to evaluate various options.

\section{Conclusions}

During the last century, researchers have concentrated on finding engineering solutions to problems of waste management, particularly those of treatment and disposal. However, engineering solutions are not capable of solving all problems of waste. In many cases, they only eliminate the symptoms and do not touch the core problems of how to reduce waste generation in the first place and how to recycle waste efficiently to the industrial-production system. As a multitude of pressures on waste management and recycling arise, attitudes toward waste and waste management need to shift toward managing and utilizing waste as a resource, thereby seeking greater co-benefits for the environment, the economy, and society. This chapter describes a simulation system that can be used to assess urban environmental technologies; this system could become a flexible tool that would permit decision makers to evaluate the impacts of various technological and policy options. Because this approach examines future scenarios contingent on various local conditions, it is difficult to establish common databases and solutions, except for the input and output data for standard technologies. It is therefore important and necessary to revise the methodology and to establish guidelines on how such simulation systems could be applied for different purposes.

\section{Acknowledgement}

This research is supported by "Integrative Environmental Planning and Evaluation System to Design Environmental Policy and Technology Scenarios for Asian Metropolitan Cities" (2007-2010) and "The design and application of low-carbon districts" (2011-2013) of National Institute for Environmental Studies and Nagoya University, Japan. 


\section{References}

Achillas, C., Vlachokostas, C., Moussiopoulos, N., \& Banias, G. (2010). Decision support system for the optimal location of electrical and electronic waste treatment plants: A case study in Greece. Waste Management, 30(5), 870-879.

Al-Salem, S. M., Lettieri, P., \& Baeyens, J. (2009). Recycling and recovery routes of plastic solid waste (PSW): A review. Waste Management, 29(10), 2625-2643.

Bai, R. B., \& Sutanto, M. (2002). The practice and challenges of solid waste management in Singapore. Waste Management, 22(5), 557-567.

Banar, M., Cokaygil, Z., \& Ozkan, A. (2009). Life cycle assessment of solid waste management options for Eskisehir, Turkey. Waste Management, 29(1), 54-62.

Cadena, E., Colon, J., Artola, A., Sanchez, A., \& Font, X. (2009). Environmental impact of two aerobic composting technologies using life cycle assessment. International Journal of Life Cycle Assessment, 14(5), 401-410.

Chen, K. C., Huang, S. H., \& Lian, I. W. (2010). The development and prospects of the endof-life vehicle recycling system in Taiwan. Waste Management, 30(8-9), 1661-1669.

Chen, X., Xi, F., Geng, Y., \& Fujita, T. (2011). The potential environmental gains from recycling waste plastics: Simulation of transferring recycling and recovery technologies to Shenyang, China. Waste Management, 31, 168-179.

Cleary, J. (2009). Life cycle assessments of municipal solid waste management systems: A comparative analysis of selected peer-reviewed literature. Environment International, 35(8), 1256-1266.

Deppe, M., Leatherwood, T., Lowitt, P., \& Warner, N. (2000). A Planner's Overview of EcoIndustrial Development. (Paper presented at the APA National Planning Conference, New York, New York).

Ekvall, T., Assefa, G., Bjöklund, A., Eriksson, O., \& Finnveden, G. (2007). What life-cycle assessment does and does not do in assessments of waste management. Waste Management, 27(8), 989-996.

Ekvall, T., \& Weidema, B. P. (2004). System boundaries and input data in consequential life cycle inventory analysis. International Journal of Life Cycle Assessment, 9(3), 161-171.

Finnveden, G., Hauschild, M. Z., Ekvall, T., Guinée, J., Heijungs, R., Hellweg, S., et al. (2009). Recent developments in Life Cycle Assessment. Journal of Environmental Management, 91(1), 1-21.

Finnveden, G., Johansson, J., Lind, P., \& Moberg, A. (2005). Life cycle assessment of energy from solid waste: Part 1: General methodology and results. Journal of Cleaner Production, 13(3), 213-229.

GEC (2005). Eco-Towns in Japan: Implications and Lessons for Developing Countries and Cities. Osaka: Global Environment Center Foundation [Electronic Version]. Retrieved Apr. 2011, from http://www.unep.or.jp/ietc/Publications/spc/Eco_Towns_in_Japan.pdf

Geng, Y., Fujita, T., \& Chen, X. (2010). Evaluation of innovative municipal solid waste management through urban symbiosis: A case study of Kawasaki. Journal of Cleaner Production, 18(10-11), 993-1000.

Habara, H., Matsuto, T., Tanaka, N., \& Inoue, M. (2002). Comparative study on regional solid waste management system in terms of cost and energy consumption (in Japanese). Environmental Systems Research, 30, 323-332.

Hostovsky, C. (2006). The paradox of the rational comprehensive model of planning: Tales from waste management planning in Ontario, Canada. Journal of Planning Education and Research, 25(4), 382-395. 
Houillon, G., \& Jolliet, O. (2005). Life cycle assessment of processes for the treatment of wastewater urban sludge: energy and global warming analysis. Journal of Cleaner Production, 13(3), 287-299.

Jang, Y. C., Lee, C., Yoon, O. S., \& Kim, H. (2006). Medical waste management in Korea. Journal of Environmental Management, 80(2), 107-115.

JCPRA. (2007). The Environmental Impacts of Plastic Containers and Packaging Recycling (in Japanese). Tokyo: The Japan Containers and Packaging Recycling Association.

Jin, J. J., Wang, Z. S., \& Ran, S. H. (2006). Solid waste management in Macao: Practices and challenges. Waste Management, 26(9), 1045-1051.

Kim, M. H., \& Kim, J. W. (2010). Comparison through a LCA evaluation analysis of food waste disposal options from the perspective of global warming and resource recovery. Science of the Total Environment, 408(19), 3998-4006.

Klinglmair, M., \& Fellner, J. (2010). Urban mining in times of raw material shortage. Journal of Industrial Ecology, 14(4), 666-679.

Levis, J. W., Barlaz, M. A., Themelis, N. J., \& Ulloa, P. (2010). Assessment of the state of food waste treatment in the United States and Canada. Waste Management, 30(8-9), 14861494.

Liamsanguan, C., \& Gheewala, S. H. (2008). The holistic impact of integrated solid waste management on greenhouse gas emissions in Phuket. Journal of Cleaner Production, 16(17), 1865-1871.

Louis, G. E. (2004). A Historical Context of Municipal Solid Waste Management in the United States. Waste Management and Research, 22(4), 306-322.

Lundie, S., \& Peters, G. M. (2005). Life cycle assessment of food waste management options. Journal of Cleaner Production, 13(3), 275-286.

Ongondo, F. O., Williams, I. D., \& Cherrett, T. J. How are WEEE doing? A global review of the management of electrical and electronic wastes. Waste Management, 31(4), 714-730.

SEPA. (2007). The Resolution on Administrative Review Requested by Qian Zuosheng, Li Huilan et al. (in Chinese). [Electronic Version]. Retrieved Nov. 2008, from http://www.mep.gov.cn/law/fzjs/xzfy/200706/t20070612_105077.htm

Shan, C. S. (2010). Projecting municipal solid waste: The case of Hong Kong SAR. Resources Conservation and Recycling, 54(11), 759-768.

Shenyang Statistical Yearbook, 2009. Shenyang Statistics Bureau, The Investigation Group of National Statistics Bureau in Shenyang: Shenyang.

Tarr, J. A. (1985). Historical perspectives on hazardous wastes in the United States. Waste Management \& Research, 3(2), 95-102.

Van Berkel, R., Fujita, T., Hashimoto, S., \& Geng, Y. (2009). Industrial and urban symbiosis in Japan: Analysis of the eco-town program 1997-2006. Journal of Environmental Management, 90, 1544-1556.

Wanichpongpan, W., \& Gheewala, S. H. (2007). Life cycle assessment as a decision support tool for landfill gas-to energy projects. Journal of Cleaner Production, 15(18), 1819-1826.

Xinhuan News Agency. (2009). Wen Jiabao at the summit meeting on climate change: The speech (full text) (in Chinese). [Electronic Version]. Retrieved May 26, 2010, from http://www.gov.cn/ldhd/2009-12/19/content_1491149.htm

Yuan, Z., Bi, J., \& Moriguichi, Y. (2006). The circular economy: A new development strategy in China. Journal of Industrial Ecology, 10(1-2), 4-8. 


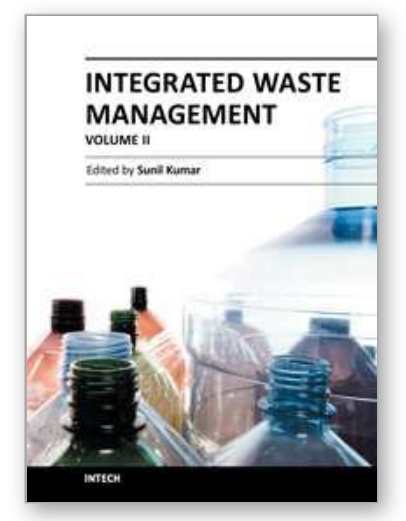

\author{
Integrated Waste Management - Volume II \\ Edited by Mr. Sunil Kumar
}

ISBN 978-953-307-447-4

Hard cover, 472 pages

Publisher InTech

Published online 23, August, 2011

Published in print edition August, 2011

This book reports mostly on institutional arrangements under policy and legal issues, composting and vermicomposting of solid waste under processing aspects, electrical and electronic waste under industrial waste category, application of GIS and LCA in waste management, and there are also several research papers relating to $\mathrm{GHG}$ emission from dumpsites.

\title{
How to reference
}

In order to correctly reference this scholarly work, feel free to copy and paste the following:

Xudong Chen, Tsuyoshi Fujita, Yong Geng and Fengming Xi (2011). Exploring and Assessing Innovative Approaches to Utilizing Waste as a Resource: Toward Co-Benefits, Integrated Waste Management - Volume II, Mr. Sunil Kumar (Ed.), ISBN: 978-953-307-447-4, InTech, Available from:

http://www.intechopen.com/books/integrated-waste-management-volume-ii/exploring-and-assessinginnovative-approaches-to-utilizing-waste-as-a-resource-toward-co-benefits

\section{INTECH}

open science | open minds

\author{
InTech Europe \\ University Campus STeP Ri \\ Slavka Krautzeka 83/A \\ 51000 Rijeka, Croatia \\ Phone: +385 (51) 770447 \\ Fax: +385 (51) 686166 \\ www.intechopen.com
}

\author{
InTech China \\ Unit 405, Office Block, Hotel Equatorial Shanghai \\ No.65, Yan An Road (West), Shanghai, 200040, China \\ 中国上海市延安西路65号上海国际贵都大饭店办公楼 405 单元 \\ Phone: +86-21-62489820 \\ Fax: $+86-21-62489821$
}


(C) 2011 The Author(s). Licensee IntechOpen. This chapter is distributed under the terms of the Creative Commons Attribution-NonCommercialShareAlike-3.0 License, which permits use, distribution and reproduction for non-commercial purposes, provided the original is properly cited and derivative works building on this content are distributed under the same license. 